\title{
Glutaric Aciduria Type II: In Vitro Studies on Substrate Oxidation, Acyl-CoA Dehydrogenases, and Electron-Transferring Flavoprotein in Cultured Skin Fibroblasts
}

\author{
WILLIAM RHEAD, ${ }^{(25)}$ STEPHANOS MANTAGOS, ${ }^{(26)}$ AND KAY TANAKA ${ }^{(28)}$ \\ Department of Human Genetics, Yale University School of Medicine, New Haven, Connecticut, USA
}

\begin{abstract}
Summary
The previous biochemical evidence had suggested that glutaric aciduria type II (GA II) is due to deficient dehydrogenation of multiple short-chain acyl coenzyme $A$ 's (CoA's), but the precise biochemical mechanism underlying this disease was unknown. We investigated substrate oxidation and in vitro activities of isovaleryl CoA- and butyryl CoA dehydrogenases as well as that of electrontransferring flavoprotein (ETF) in cultured skin fibroblasts from a patient with GA II. GA II cells have a markedly decreased ability to oxidize $\left[1-{ }^{14} \mathrm{C} \mid b u t y r a t e,\left[2-{ }^{14} \mathrm{C}\right]\right.$ ysine, and $\left[2-{ }^{14} \mathrm{C}\right]$ leucine (3, 9, and $9 \%$ of control values, respectively). Mitochondrial isovaleryl CoA- and butyryl CoA dehydrogenase activities in GA II cells were determined using a tritium release assay with $\left[2,3-{ }^{3} \mathrm{H}\right]$ acyl-CoA's as substrates. When an artificial electron acceptor, phenazine methosulfate (PMS) was not added in the assay media, these activities were 108 and $113 \%$ of controls, respectively. This represents the normal abilities of the dehydrogenases in GA II cells to bind the substrate and to catalyze tritium exchange between the bound substrate and solvent. When PMS was added to the assay mixture, these activities were 88 and $70 \%$ of control values, respectively, indicating that these enzymes can both dehydrogenate their substrates normally and then transfer electrons to an acceptor (PMS).

ETF activity in mitochondrial sonic supernatants from GA II cells, as assessed by a newly devised method, was $159 \%$ of control values. These observations suggest that the acyl CoA dehydrogenases themselves and ETF are not defective in GA II. Therefore, the deficiency of another common gene product necessary for the function of all the affected acyl $\mathrm{CoA}$ dehydrogenases must be sought to explain the etiology of GA II.
\end{abstract}

\section{Speculation}

Inasmuch as the data presented in this paper and those available in the literature suggest that deficiencies of the cofactors involved in short-chain fatty acid metabolism (flavin adenine dinucleoside, coenzyme A, and carnitine) are also unlikely in GA II, other possibilities must be investigated. $A$ unique iron-sulfur flavoprotein (electron-transferring flavoprotein dehydrogenase) has been isolated from beef heart mitochondria that appears to catalyze electron transfer from the reduced electron-transferring flavoprotein to coenzyme Q. Experiments are in progress to determine if this protein is present and catalytically active in glutaric aciduria type II fibroblasts.

Glutaric aciduria type II (GA II) is an inborn error of metabolism characterized by hypoglycemia, metabolic acidosis, and a complex organic aciduria consisting of glutaric, ethylmalonic, isovaleric, $\alpha$-methylbutyric, isobutyric, and hexanoic acids, as well as aliphatic dicarboxylic acids $(5,14)$. This disease was named GA
II because glutarate was by far the predominant urinary metabolite in the original patient (14) and because it differed from glutaric aciduria (type I) in which only glutarate and its metabolites (glutaconate and 3-hydroxyglutarate) accumulate (6). GA II may be fatal in the neonatal period for infants affected with the severest form of the disorder, although a less severe form exists (5). In addition, a patient with ethylamalonic-adipic aciduria (EMA) has recently been described (12). In this disease, urinary metabolites are most often the same as those found in GA II except conspicuously low or absent excretion of glutarate. It has been demonstrated that the in vitro oxidation of ${ }^{14} \mathrm{C}$-labeled glutaric acid, leucine, isoleucine, and valine by intact GA II fibroblasts was depressed (14). These results, coupled with the metabolite analyses in vivo, led to the hypothesis that dehydrogenation of multiple acyl coenzyme A's (CoA's) is deficient in this disorder (Fig. 1) (14). A similar pattern of metabolic blockade has also been observed in EMA fibroblasts (12). Because some of the short-chain acyl CoA's accumulated in GA II and EMA are known to be dehydrogenated by separate acyl CoA dehydrogenases $(3,8,13,16)$, deficiency of another protein whose activity is essential to the function of all the involved dehydrogenases has been postulated as the mechanism underlying these two diseases $(12,14)$. It is not known at present whether GA II and EMA result from allelic mutations of the same gene or if they are due to mutations in two different genes.

In an attempt to elucidate the biochemical basis of GA II, we have investigated the oxidation of ${ }^{14} \mathrm{C}$-labeled butyrate, lysine, leucine, and succinate by intact skin fibroblasts from the original patient with GA II. In addition, we have assayed two enzymes, isovaleryl CoA and butyryl CoA dehydrogenases, as well as electron-transferring flavoprotein (ETF) (Fig. 2) in mitochondria isolated from GA II fibroblasts. This investigation was carried out with two new assay methods recently developed in our laboratory. These are the tritium release assay for isovaleryl CoA and butyryl CoA dehydrogenases $(15,16)$ and a dye reduction assay for ETF.

\section{MATERIALS AND METHODS}

$\left[2,3-{ }^{3} \mathrm{H}\right]$ Isovaleric acid $(10 \mathrm{mCi} / \mathrm{mmole})$ and $\left[2,3-{ }^{3} \mathrm{H}\right]$ butyric acid $(10 \mathrm{mCi} / \mathrm{mmole})$ were synthesized by New England Nuclear, Boston, MA. Coenzyme A esters of the free acids were synthesized by the mixed anhydride method in our laboratory (23). The tritiated acyl CoA's were found to be 89 to $98 \%$ pure as analyzed by paper chromatography using ethanol:0.1 $\mathrm{M}$ potassium acetate buffer ( $\mathrm{pH} 4.5$ ) mixture (1:1) as a developing solvent. Pure pig liver general acyl CoA dehydrogenase was a gift from Dr. Carole L. Hall, Georgia Institute of Technology, Atlanta, GA. Fibroblasts were cultured from skin biopsies of one patient with GA II and six normal individuals. The patient with GA II (14) was reported previously. Cells were grown in Eagle's minimal essential medium, supplemented with $10 \%$ fetal calf serum, glutamine, and nones- 

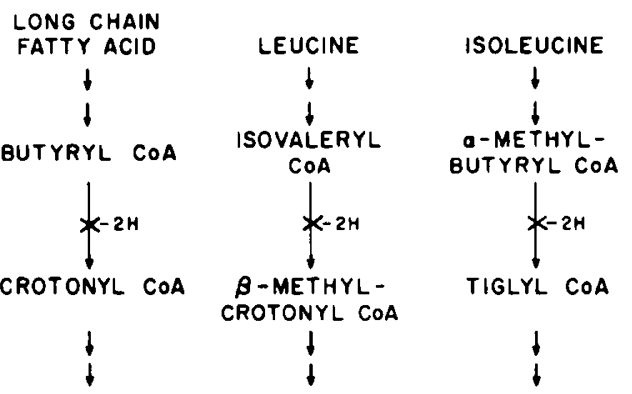

LYSINE

HYOROXYLYSINE

TRYPTOPHAN

$\downarrow$

$\downarrow$

GLUTARYL COA

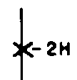

GLUTACONYL COA
Fig. 1. Pattern of metabolic blockade in glutaric aciduria type II.

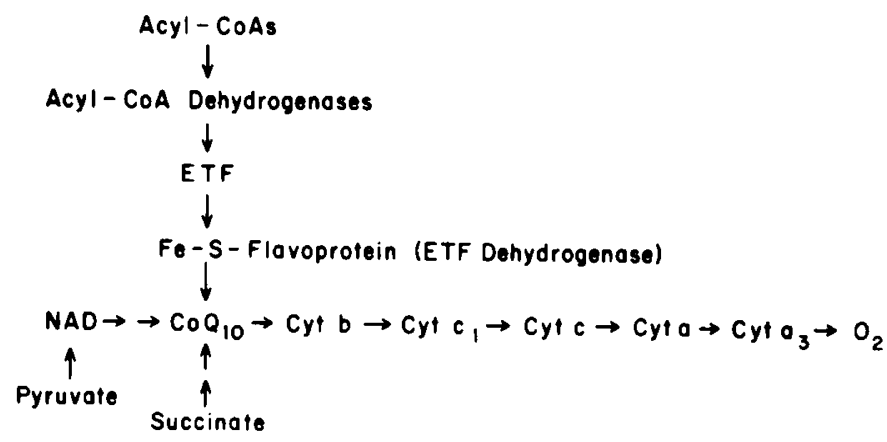

Fig. 2. Electron transport from the acyl CoA's to the mitochondrial respiratory chain.

sential amino acids. The oxidation of four radioactive substrates $\left(\left[1-{ }^{14} \mathrm{C}\right]\right.$ butyrate, $\left[2-{ }^{14} \mathrm{C}\right]$ lysine, $\left[2-{ }^{14} \mathrm{C}\right]$ leucine, and $\left[1,4-{ }^{14} \mathrm{C}\right]$ succinate) by cultured skin fibroblasts was performed as described earlier (12).

Mitochondrial acyl CoA dehydrogenase activities were determined in duplicate using the tritium release assays which we have recently described $(15,16)$. Total volume of the reaction mixture was $100 \mu \mathrm{l}$. The final concentrations of all reagents were as follows: $\mathrm{NaP}_{\mathrm{i}}, 10 \mathrm{mM}, \mathrm{pH} 7.5$; phenazine methosulfate (PMS), $18.8 \mathrm{mM}$; $\left[2,3-{ }^{3} \mathrm{H}\right]$ acyl $\mathrm{CoA}, 100 \mu \mathrm{M}$. Sonic mitochondrial supernatants $(25$ to $50 \mu \mathrm{g}$ protein per assay) were the enzyme source. Mitochondria were isolated from human fibroblasts by the method previously described (16) and were sonicated into $200 \mu \mathrm{l} \mathrm{NaP}, 12.5 \mathrm{mM}, \mathrm{pH}$ 7.5 , using a Branson sonifier with a small tip and centrifuged at $40,000 \times g$ for $30 \mathrm{~min}$. After incubation at $37^{\circ} \mathrm{C}$ for $15 \mathrm{~min}$, the reaction was stopped by addition of $5 \mu$ of $0.5 \%$ iodine in $0.5 \mathrm{M}$ $\mathrm{HCl}: 75 \%$ ethanol; a $90 \mu \mathrm{l}$ aliquot of the resulting mixture was passed over a $0.5-\mathrm{ml}$ column of AG-1 anion exchange resin [acetate form (Bio-Rad)] and packed in a pasteur pipette, and the column washed with $1 \mathrm{ml}$ deionized water. The tritium in the eluate was then quantiated by liquid scintillation. Dehydrogenase activities were also determined in the absence of phenazine methosulfate.

Mitochondrial ETF was assayed by a modification of the dye reduction method which has been used for the acyl CoA dehydrogenases (9). The basic principle of this assay is that a vast excess of pure pig liver general acyl CoA dehydrogenase (GAD) and octanoyl CoA is added to an assay mixture which contains dichlorophenol indophenol (DCIP) as a terminal electron acceptor but omits the obligatory electron transfer agent (ETF or PMS). In this system, ETF activity in the fibroblast mitochondrial sonicate is rate limiting for electron transfer from GAD to DCIP (9). The total volume of assay mix was $0.625 \mathrm{ml}$. The final concentrations of all reagents were as follows: GAD, $4.6 \mu \mathrm{g} /$ assay; octanoyl CoA, $40 \mu \mathrm{M} ; \mathrm{NaP}_{\mathrm{i}}, 10 \mathrm{mM}, \mathrm{pH} 7.5$; DCIP, $0.002 \%$. The rates of dye reduction were calculated using the absorbance change in the interval from the second to fourth min after addition of substrate.

\section{RESULTS}

Przyrembel et al. (14) have demonstrated that oxidation of ${ }^{14} \mathrm{C}$ labeled substrates, including valine, leucine, isoleucine, glutarate, $\alpha$-ketoisovalerate, and $\alpha$-ketoisocaproate by GA II fibroblasts was depressed but that pyruvate oxidation was normal. However, the degree of deficiency of these activities was somewhat obscured by their use of universally labeled substrates. The assay of $\left[1,5-{ }^{14} \mathrm{C}\right]$ glutaryl CoA oxidation in tissue homogenates from another patient with GA II has yielded confusing results; this activity was markedly deficient in liver and kidney from this patient, but was normal in fibroblasts (7).

First, we have extended the study of substrate oxidation using $\left[1-{ }^{14} \mathrm{C}\right]$ butyrate and specifically labeled leucine and lysine as substrates. The ability of GA II cells to oxidize $\left[1-{ }^{14} \mathrm{C}\right]$ butyrate, [2$\left.{ }^{14} \mathrm{C}\right]$ lysine, and $\left[2-{ }^{14} \mathrm{C}\right]$ leucine was 3,9 , and $9 \%$ of control values, respectively (Table 1 ); oxidation of $\left[1,4-{ }^{14} \mathrm{C}\right]$ succinate by GA II cells was unimpaired, suggesting that cell viability was normal (Table 1). These findings indicate that the metabolic block in GA II is expressed in cultured fibroblasts and that mitochondrial electron transport from succinate to molecular oxygen is intact in GA II cells (Fig. 2).

The activities of two acyl CoA dehydrogenases, isovaleryl CoA and butyryl $\mathrm{CoA}$, were determined using the tritium release assay both in the presence and absence of PMS $(15,16)$. When assayed in the absence of PMS, tritium is released from the enzyme-bound $\left[2,3-{ }^{3} \mathrm{H}\right]$ acyl CoA's by exchange of protons with the assay medium ("exchange") and net oxidation of the substrate does not occur (4, 15). The amount of tritium released by exchange is not dependent on the presence of electron acceptor (15), but it is catalyzed by the dehydrogenase alone. The exchange activities for isovaleryl CoA and butyryl CoA of mitochondrial sonicates from GA II cells were 108 and $113 \%$ of control values, respectively (Table 2 ). When assayed in the presence of PMS, the amounts of tritium released from $\left[2,3-{ }^{3} \mathrm{H}\right]$ isovaleryl $\mathrm{CoA}$ and $\left[2,3-{ }^{3} \mathrm{H}\right]$ butyryl $\mathrm{CoA}$ by mitochondrial sonicates from both GA II and normal cells increased 35 and $460 \%$, respectively, over those released by the exchange activities. Under such conditions, isovaleryl CoA and butyryl CoA dehydrogenase activities in GA II fibroblast mitochondria were 88 and 70\%, respectively, of control values as shown in Table 2. These results suggest that the ability of the enzymes to bind the substrate (exchange) and the ability to abstract hydrogens from the substrate and transfer them to an electron acceptor (PMS) (true dehydrogenation) are not impaired significantly in GA II.

Because ETF catalyzes the first reaction in the transfer of electrons from the reduced acyl $\mathrm{CoA}$ dehydrogenases to the respiratory chain in vivo (Fig. 2), we assayed for ETF activity in GA II fibroblast mitochondria using a modification of the traditional dye reduction assay for the acyl CoA dehydrogenases as described in "Materials and Methods." In this assay system, a vast excess of octanoyl $\mathrm{CoA}$ and pure pig liver general acyl CoA dehydrogenase (GAD) was added as the source of reduced acyl CoA dehydrogenase, and DCIP was used as the terminal electron acceptor. Sonic supernatants from GA II fibroblast mitochondria were used as the source of ETF. Reduction of DCIP by reduced GAD will only occur if ETF is present and thus provides an effective assay for ETF. The amount of ETF is rate limiting under these conditions (9). Utilizing this method, in vitro mitochondrial ETF activity in GA II fibroblasts was higher than controls on two separate occasions, averaging $159 \%$ of control values (Table 3 ), suggesting that ETF activity is not deficient in GA II.

\section{DISCUSSION}

The studies presented above demonstrate that fibroblasts from a patient with GA II are severely deficient in their ability to oxidize ${ }^{14} \mathrm{C}$-labeled butyrate, leucine, and lysine. These cells were derived from an infant who died at $70 \mathrm{hr}$ of age with hypoglycemia and metabolic acidosis (14). Biochemical analysis of this patient's urine revealed massive excretion of glutaric, ethylmalonic, isovaleric, isobutyric, $\alpha$-methylbutyric, and hexanoic acids, as well as dicarboxylic acids with 6,8 , and 10 carbons. Several related metabolites, isovaleryl- and hexanolylglycine, have recently been identified in the urine of an adult patient with GA II (5). These compounds are formed via the conjugation of the appropriate acyl CoA with glycine catalyzed by glycine $N$-acylase, a mitochondrial 
Table 1. Oxidation of $\left[1-{ }^{14} \mathrm{C}\right]$ butyrate, $\left[2-{ }^{14} \mathrm{C}\right]$ lysine, $\left[2-{ }^{14} \mathrm{C}\right]$ leucine, and $\left[1,4-{ }^{14} \mathrm{C}\right]$ succinate by cultured skin fibroblasts Oxidation

\begin{tabular}{|c|c|c|c|c|}
\hline Cells & {$\left[1-{ }^{14} \mathrm{C}\right]$ Butyrate } & $\begin{array}{c}{\left[2-{ }^{14} \mathrm{C}\right] \text { Lysine }} \\
\text { (nmoles }{ }^{14} \mathrm{CO}_{2} \text { produced/ } \\
10^{6} \text { cells } / \mathrm{hr} \text { ) }\end{array}$ & $\begin{array}{c}{\left[2-{ }^{14} \mathrm{C}\right] \text { Leucine }} \\
\text { (nmoles }{ }^{14} \mathrm{CO}_{2} \text { produced/ } \\
10^{6} \text { cells } / \mathrm{hr} \text { ) }\end{array}$ & {$\left[1,4{ }^{14} \mathrm{C}\right]$ Succinate } \\
\hline $\begin{array}{l}\text { Normal controls }(6)^{1} \\
\text { Glutaric aciduria }\end{array}$ & $2.57 \pm 0.39^{2}$ & $0.53 \pm 0.08$ & $0.47 \pm 0.03$ & $0.89 \pm 0.20$ \\
\hline type II (1) & $0.08 \pm 0.00^{3}$ & $0.05 \pm 0.00^{3}$ & $0.04 \pm 0.00^{3}$ & $0.91 \pm 0.31^{3}$ \\
\hline
\end{tabular}

' Numbers in parentheses, number of fibroblast lines.

${ }^{2}$ Mean \pm S.E.

${ }^{3}$ Mean of two experiments \pm difference from the mean.

Table 2. Isovaleryl CoA-and butyryl CoA dehydrogenase activities in mitochondria from fibroblasts of patients with glutaric aciduria type II and normal individuals

\begin{tabular}{|c|c|c|c|c|c|}
\hline \multirow{2}{*}{$\begin{array}{l}\text { Origin of mito- } \\
\text { chondria }\end{array}$} & \multirow{2}{*}{$\begin{array}{l}\text { No. of cell } \\
\text { lines }\end{array}$} & \multicolumn{2}{|c|}{$\begin{array}{l}\text { Enzymatic tritium release via artificial electron ac- } \\
\text { ceptor' (pmoles product } / \mathrm{min} / \mathrm{mg} \text { protein) }\end{array}$} & \multicolumn{2}{|c|}{$\begin{array}{c}\text { Tritium exchange catalyzed by enzyme alone } \\
\text { (pmoles product/min/mg protein) }\end{array}$} \\
\hline & & IVCD $^{2}$ & BCD & IVCD & BCD \\
\hline $\begin{array}{l}\text { Normal cells } \\
\text { Glutaric aciduria }\end{array}$ & 4 & $276 \pm 43^{3}$ & $462 \pm 133$ & $49.7 \pm 4.5$ & $208 \pm 21$ \\
\hline type II cells & 1 & 243 & 322 & $53.7 \pm 19^{4}$ & $237 \pm 53^{4}$ \\
\hline
\end{tabular}

' Phenazine methosulfate, $18.8 \mathrm{mM}$.

${ }^{2}$ IVCD, isovaleryl CoA dehydrogenase; BCD, butyryl CoA dehydrogenase.

${ }^{3}$ Mean \pm S.E.

${ }^{4}$ Assayed on two occasions.

Table 3. Electron-transferring flavoprotein activity in mitochondria from fibroblasts of patients with glutaric aciduria type II and normal individuals

\begin{tabular}{lcc}
\hline $\begin{array}{c}\text { Origin of mito- } \\
\text { chondria }\end{array}$ & No. of cell lines & $\begin{array}{c}\text { Specific activity } \\
\text { (nmoles DCIP reduced/ } \\
\text { min/mg protein) }\end{array}$ \\
\hline $\begin{array}{l}\text { Normal cells } \\
\begin{array}{c}\text { Glutaric aciduria } \\
\text { type II cells }\end{array}\end{array}$ & $3(5)^{2}$ & $3.74 \pm 0.29$ \\
\hline
\end{tabular}

${ }^{1}$ Mean \pm S.E.

${ }^{2}$ Numbers in parentheses, number of determinations.

enzyme; free carboxylic acids represent very poor substrates for this enzyme $(2,20)$. It has also been shown that ethylmalonic acid is formed by carboxylation of butyryl CoA in mitochondria (21) when oxidation of butyryl CoA is inhibited (1). Thus, the pattern of metabolite accumulation, coupled with cell oxidation studies, suggests that in GA II and EMA the metabolism of multiple substrates is blocked at the step of acyl CoA dehydrogenation (Fig. 1) $(5,12,14)$.

Because many of the acyl CoA dehydrogenase activities deficient in GA II, including those for butyryl-, isovaleryl-, and glutaryl CoA, are presumably regulated by different genes $(3,8$, $9,13,16$ ), we must postulate a deficiency of a common gene product whose activity is essential to the function of all the affected dehydrogenases. Acyl CoA dehydrogenation in vivo is a complicated reaction which requires enzymes and proteins other than the dehydrogenases alone (Fig. 2). Thus, pertinent possibilities for the etiology of GA II include deficiency of carinitine-dependent mitochondrial transport of acyl CoA's (22), of cofactors and coenzymes [CoA or flavin adenine dinucleoside (FAD)], of a protein component or subunit common to all the acyl $\mathrm{CoA}$ dehydrogenases, or of proteins required for electron transport from the reduced acyl CoA dehydrogenases to coenzyme $Q$ in the electron transport chain: ETF or iron-sulfur flavoprotein (ETF dehydrogenase) (Fig. 2) $(9,18,19)$. Carinitine deficiency as the cause of GA II is excluded because the pattern of metabolite accumulation in GA II is distinctly different from that observed in patients with systemic carnitine deficiency who do not excrete ethylmalonic and glutaric acids and acylglycines (11). The accumulation of urinary ethylmalonic acid, isovalerylglycine, and hexanoylglycine in patients with GA II indicates that butyryl CoA, isovaleryl CoA, and hexanoyl CoA are present inside the mitochondria. This also argues against intramitochondrial carnitine deficiency as well as a deficiency of the synthesis or intracellular content of CoA.

Our data presented in Table 2 suggest that isovaleryl CoA- and butyryl CoA dehydrogenases are both functionally normal in GA II because the abilities of mitochondrial sonic supernatants to bind substrate and to catalyze tritium exchange from substrate to solvent in the absence of PMS (exchange activity) and to transfer electrons to PMS (or "true dehydrogenase" activity) are not altered in GA II fibroblasts. Thus, it appears that a primary deficiency of the dehydrogenases is not the etiology of this disorder. This finding also excludes the possibility of a defective protein component or subunit common to all the acyl CoA dehydrogenases as the mechanism underlying GA II. This result is also consistent with the evidence that all three straight chain acyl CoA dehydrogenases (butyryl CoA-, general acyl CoA- and long-chain acyl CoA dehydrogenases) are tetramers of identical subunits $\left(\alpha_{4}\right)(9)$. These data are in sharp contrast to our findings in isovaleric acidemia fibroblasts; we have recently shown, using the tritium release assay with PMS, that isovaleryl CoA dehydrogenase activity is markedly decreased (13\% of normal controls) in five isovaleric acidemia cell lines, whereas butyryl CoA dehydrogenase activity is preserved at normal levels (16). Both isovaleryl CoA and butyryl CoA dehydrogenase activities were consistently lower (approximately 50\% of controls, respectively) in EMA cells than in GA II cells (17).

Normal oxidation of ${ }^{14} \mathrm{C}$-succinate by GA II fibroblasts implies that succinic dehydrogenase, a FAD-requiring enzyme, is not deficient in these cells and is evidence against a defect in the synthesis of FAD (Table 1). In addition, there is some preliminary data suggesting that incorporation of ${ }^{14} \mathrm{C}$-labeled riboflavin into flavin-containing cofactors is normal in GA II (7). Normal succinate catabolism also suggests that the mitochondrial electron transport chain is functionally normal from coenzyme $Q$ to cytochromes $a$ and $a_{3}$ (Fig. 2) (10). In summary, deficiencies of a common dehydrogenase subunit, or of FAD, CoA, or carnitine biosynthesis can be excluded as the etiology of GA II from the evidence presented here and elsewhere.

Thus, the currently available evidence is consistent with the metabolic defect in GA II being in electron transport from the 
acyl CoA dehydrogenases to coenzyme $Q_{10}$ (Fig. 2) and is probably due to a deficiency of one of the two flavoproteins, ETF or ETF dehydrogenase (iron-sulfur flavoprotein), involved in this segment of the electron transfer chain $(9,10,19)$. Absence of either enzyme would presumably block electron flow to coenzyme $Q$ and, secondarily, acyl CoA dehydrogenation, giving rise to both the metabolite accumulation and defective substrate oxidation observed in vivo and in vitro, respectively, because ETF is a dimer of identical subunits and iron-sulfur flavoprotein is a monomer, a defective single gene product could account for all the biochemical findings in this disorder. However, the data presented in Table 3 suggest that GA II fibroblast mitochondria can catalyze normal rates of electron transfer between general acyl CoA dehydrogenase and an artificial terminal electron acceptor, implying that ETF is not deficient in GA II. Although the studies on ETF should be regarded as preliminary, experiments are in progress to quantitate more precisely the levels and activity of ETF as well as that of ETF dehydrogenase in GA II and EMA cells.

\section{REFERENCES AND NOTES}

1. Baretz, B. H Lollo, C. P. and Tanaka, $K$ : Metabolism in rats in vivo of RS-2 methylbutyrate and $n$-butyrate labeled with stable isotopes at various positions: mechanism of biosynthesis and degradation of ethylmalonyl semialdehyde and ethylmalonic acid. J. Biol. Chem., 254: 3468 (1979).

2. Bartlett, K., and Gompertz, D.: The specificity of glycine- $N$-acylase and acylglycine excretion in the organic acidemias. Biochem. Med., 10: 15 (1974).

3. Besrat, A., Polan, C. E., and Henderson, L. M.: Mammalian metabolism of glutaric acid. J. Biol. Chem., 244: 1461 (1969).

4. Bielman, J. F., and Hirth, C. G.: Stereochemistry of the oxidation at the $\beta$-carbon of butyryl-SCoA. FEBS Lett., 8: 55 (1970).

5. Dusheiko, G., Kew, M., Joffe, B., Lewin, J., Mantagos, S., and Tanada, K.: Glutaric aciduria type II: a cause of recurrent hypoglycemia in an adult. $\mathrm{N}$. Engl. J. Med., 301: 1405 (1979).

6. Goodman, S. I., Markey, S. P.. Moe, P. G., Miles, B. S., and Teng, C. C.: Glutaric aciduria: a "new" disorder of amino acid metabolism. Biochem. Med., 12: 12 (1975).

7. Goodman, S. I., McCabe. E. R. B., Fennessey, P. V., and Mace. J. W.: Multiple acyl-CoA dehydrogenase deficiency (glutaric aciduria type II) with transient hypersarcosinemia and sarcosinuria: possible inherited deficinecy of an electron transfer flavoprotein. Pediatr. Res., 14: 12 (1980).

8. Green, D. E., and Allman, D. W.: Fatty acid oxidation. In: D. M. Greenberg Metabolic Pathways. Vol. 2, pp 1-36 (Academic Press, Inc., New York, 1968).

9. Hall, C.: Acyl CoA dehydrogenases and electron-transferring flavoprotein. Methods Enzymol., 53: 502 (1978).

10. Hatefi, Y., Hanstein, W., Galante, Y., and Stigall, D.: Mitochondrial ATP-P exchange complex and the site of uncoupling of oxidative phosphorylation. Fed. Proc., 34: 1699 (1975)
1. Karpati, G., Carpenter, S., Engel, A., Watters, G., Allen, J., Rothman, S., Klassen, G., and Mamer, O.: The syndrome of systemic carnitine deficiency. Neurology. 25: 16 (1975)

12. Mantagos, S., Genel, M.. and Tanaka, K.: Ethylmalonic-adipic aciduria: in vivo and in vitro studies indicating deficiency of activities of multiple acyl-CoA dehydrogenases. J. Clin. Invest., 64: 1580 (1979).

13. Noda, C., Rhead, W. J., and Tanaka, K.: Isovaleryl CoA dehydrogenase: demonstration in rat liver mitochondria by ion exchange chromatography and isoelectric focusing. Proc. Natl. Acad. Sci., 77: 2646 (1980).

14. Przyrembel, H., Wendel, U., Becker, K., Bremer, H., Bruinvis, L., Ketting, D., and Wadman, S.: Glutaric aciduria type II: report on a previously undescribed metabolic disorder. Clin. Chim. Acta, 66: 227 (1976).

15. Rhead. W., and Tanaka, K.: Development of a tritium release assay for isovaleryl CoA dehydrogenase and characterization of this enzyme in rat liver mitochondria. Fed. Proc., 38: 648 (1979).

16. Rhead. W., and Tanaka. K.: Demonstration of a specific mitochondrial isovaleryl CoA dehydrogenase deficiency in fibroblasts from patients with isovaleric acidemia. Proc. Natl. Acad. Sci., 77: 580 (1980).

17. Rhead, W. J., and Tanaka, K.: (unpublished observation).

18. Ruzicka, F., and Beinert, H.: A new membrane iron-sulfur flavoprotein of the mitochondrial electron transport system. Biochem. Biophys. Res. Commun. 66: 622 (1975)

19. Ruzicka, F., and Beinert, H.: A new iron-sulfur flavoprotein of the respiratory chain. J. Biol. Chem., 252: 8440 (1977)

20. Sachter. D., and Taggart. J. V.: Glycine $\boldsymbol{N}$-acylase: purification and properties. J. Biol. Chem., 208: 263 (1954).

21. Stern, J. R., Friedman, D. L., and Menon, G. K. K.: Enzymic carboxylation of butyryl CoA. I. Conversion of butyryl CoA to 2-ethylmalonyl CoA. Arch. Biochem. Biophys., 92: 280 (1961).

22. Van Hinsbergh, V., Veerkamp, J., Engelen, P., and Ghijsen, W.: Effect of Lcarnitine on the oxidation of leucine and valine by rat skeletal muscle. Biochem. Med., 20: 115 (1978)

23. Wieland, T., and Rueff, L.: Synthese von S- $\beta$-oxybutyryl- und S-Acetyl-Coenzym A. Angew. Chem., 65: 186 (1953).

24. A preliminary verision of this work has been published in Am. J. Hum. Genet., 31: 59A (1979).

25. The present address of William Rhead is: Division of Medical Genetics, Department of Pediatrics, University of Iowa Hospitals and Clinics, lowa City, IA 52242 (USA).

26. The present address of Stephanos Mantagos is: Department of Pediatrics, Division of Medical Genetics, Nassau County Medical Center, East Meadow, NY 11552 (USA).

27. The authors would like to thank Dr. H. Bremer for the provision of the glutaric aciduria type II cell line used in this study and Dr. Carole L. Hall for the gift of ETF, as well as Melanie Ball and Marilyn Feldman for the technical and clerical assistance, respectively.

28. Requests for reprints should be addressed to: Dr. Kay Tanaka, Department of Human Genetics, Yale University School of Medicine, 333 Cedar Street. New Haven, CT 06510 (USA).

29. This research was supported by a grant from the National Foundation-March of Dimes (1-378) and an NIH grant (AM 17453).

30. Received for publication February 4, 1980.

31. Accepted for publication March 24, 1980. 